\title{
Development, manufacture and initial assessment of validity of a 3-dimensional-printed bowel anastomosis simulation training model
}

\author{
Katie Oxford, BMSc \\ Greg Walsh, BEng \\ Jonathan Bungay \\ Stephen Quigley, MD \\ Adam Dubrowski, PhD
}

Accepted Oct. 28, 2020

\section{Correspondence to: K. Oxford \\ Department of Medicine \\ Memorial University of Newfoundland \\ 193 Empire Ave \\ St. John's NL A1C 5S7 \\ kpoxford@mun.ca}

Cite as: Can J Surg 2021 September 22; 64(5). doi: $10.1503 /$ cjs. 018719

\begin{abstract}
Background: It is critical that junior residents be given opportunities to practise bowel anastomosis before performing the procedure in patients. Three-dimensional (3D) printing is an affordable way to provide realistic, reusable intestinal simulators. The aim of this study was to test the face and content validity of a 3D-printed simulator for bowel anastomosis.
\end{abstract}

Methods: The bowel anastomosis simulator was designed and assembled with the use of desktop 3D printers and silicone solutions. The production cost ranges from $\$ 2.67$ to $\$ 131$, depending on which aspects of the model one prefers to include. We incorporated input from a general surgeon regarding design modifications to improve the realism of the model. Nine experts in general surgery (6 staff surgeons and 3 senior residents) were asked to perform an anastomosis with the model and then complete 2 surveys regarding face and content validity. Items were rated on a 5-point Likert scale ranging from 1 ("strongly disagree") to 5 ("strongly agree").

Results: The overall average score for product quality was 3.58, indicating good face validity. The average score for realism (e.g., flexibility and texture of the model) was 3.77. The simulator was rated as being useful for training, with an overall average score of 3.98. In general, the participants agreed that the simulator would be a valuable addition to current simulation-based medical education (average score 4.11). They commented that the model would be improved by adding extra layers to simulate mucosa.

Conclusion: Experts found the 3D-printed bowel anastomosis simulator to be an appropriate tool for the education of surgical residents, based on the model's texture, appearance and ability to undergo an anastomosis. This model provides an affordable way for surgical residents to learn bowel anastomosis. Future research will focus on proving educational efficacy, effectiveness and transfer that can be adapted for laparoscopic anastomosis training, hand-sewing and stapling procedures.

Contexte : Il est crucial que les résidents juniors aient l'occasion de s'exercer à l'anastomose intestinale avant d'intervenir sur des patients. L'impression en 3 dimensions (3D) est une façon abordable de produire des simulateurs intestinaux réalistes et réutilisables. Le but de cette étude était de vérifier la validité apparente et de contenu des simulateurs obtenus par impression 3D pour l'anastomose intestinale.

Méthodes : Le simulateur d'anastomose intestinale est conçu et assemblé avec des imprimantes de bureau $3 \mathrm{D}$ et des solutions de silicone. Le coût de fabrication varie de $2,67 \$$ à 131 \$, selon le nombre de composants désiré. Suite aux commentaires d'un chirurgien général nous avons modifié le modèle afin de le rendre plus réaliste. Nous avons demandé à 9 experts en chirurgie générale (6 chirurgiens en poste et 3 résidents séniors) d'effectuer une anastomose sur le modèle, puis de répondre à 2 questionnaires sur sa validité apparente et de contenu. Les questions étaient notées sur une échelle de Likert en 5 points, allant de 1 (« en désaccord total ») à 5 (《 tout à fait d'accord »).

Résultats : Le score moyen global pour la qualité du produit a été de 3,58, soit une bonne validité apparente. Le score moyen pour le réalisme (p. ex., flexibilité et texture du modèle) a été de 3,77. Le simulateur a été jugé utile pour la formation, avec un score moyen global de 3,98. En général, les participants ont convenu que le simulateur serait un ajout précieux à la formation actuelle par simulation (score moyen 4,11). Ils ont formulé un commentaire à l'effet que le modèle gagnerait à comporter des couches supplémentaires pour simuler la muqueuse.

Conclusion : Les experts ont jugé que le simulateur d'anastomose intestinale 3D constitue un outil approprié pour la formation des résidents en chirurgie, du point de vue de la texture et de l'aspect du modèle et de la capacité de pratiquer l'anastomose. Ce modèle constitue une façon abordable d'apprendre comment effectuer une anastomose intestinale pour les résidents en chirurgie. La recherche à venir portera sur la détermination de son efficacité didactique, son efficacité et de son applicabilité à l'enseignement de la technique d'anastomose laparoscopique, de la suture à la main et des techniques d'agrafage. 


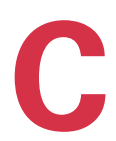
olectomy, a procedure involving bowel anastomosis, ${ }^{1}$ is considered to be among the top 10 highvolume inpatient surgical procedures performed in Newfoundland and Labrador, Nova Scotia, Manitoba, British Columbia, Nunavut and Yukon. ${ }^{2}$ From 2017 to 2018, 4940 colectomy procedures were performed in those provinces, including 501 in Newfoundland and Labrador alone. ${ }^{2}$ This is only 1 example of the many surgical procedures that require bowel anastomosis.

One of the most common complications during any anastomosis procedure is leakage. ${ }^{3}$ Complications due to poor stitching or stapling can lead to very severe complications, including death. ${ }^{4}$ In a literature review analyzing information from 1980 to 2007, the rate of leakage after anastomosis ranged from $2.9 \%$ to $15.9 \%$, depending on the procedure and experience of the surgeon, ${ }^{5}$ which highlights the importance of training. Developing the skills to perform a proper bowel anastomosis requires a substantial amount of time and practice. However, learners may not always have the opportunity to practise hand-sewn anastomosis in the operating room. ${ }^{6}$ Resident work-hour restrictions ${ }^{3}$ and emphasis on novel techniques such as stapling have decreased practical exposure to hand-sewn bowel anastomoses. ${ }^{6}$ This decrease in exposure is unfavourable, as the handsewn small bowel anastomosis is one of the "most basic and fundamental skills burgeoning young surgeons must learn."”

In recent years, many surgical skills have been taught with the use of simulators created by 3-dimensional (3D) printing. Simulators are now available to enhance skills in many surgical procedures, such as laparoscopic pyloromyotomy, and have been determined to be useful for training purposes. ${ }^{8}$ Perineal repair models have also been developed with the use of $3 \mathrm{D}$ printing. ${ }^{9}$

Similarly, hand-sewn small bowel anastomosis can be learned on a variety of simulators. ${ }^{6}$ Residents have been trained using porcine and bovine models.,10-12 These models provide excellent textural simulation but are more difficult to standardize and require an additional preservation step to ensure that the tissues do not decompose. Alternatively, inanimate simulators, including foam and felt models, ${ }^{7,11}$ can be used; however, these models are often poor simulators of bowel mucosa or are very expensive. ${ }^{7}$ For example, SurgiReal Products offers a bowel anastomosis model that costs Can $\$ 156.70$. There are more affordable silicone options, such as a model produced by Sim*Vivo (about Can\$25), but this option is still more expensive than the smallest functional unit of the model presented here. In addition, many commercial models are built and sold primarily for profit.

We describe an inexpensive, easily variable bowel anastomosis simulation model for teaching hand-sewn anastomosis, manufactured via $3 \mathrm{D}$ printing and silicone pouring techniques. The goal of this project was to determine whether the simulator constitutes a realistic, inexpensive and potentially effective simulator.

\section{Methods}

\section{Model}

The bowel anastomosis simulator was composed of 5 main parts: the top skin layer (Figure 1A), the base (Figure 1B), small intestine $\mathrm{U}$-shaped connectors (Figure 2A), small intestine joints (Figure 2B) and large intestine (Figure 3). We made all of these parts from Smooth-On silicone that had been dyed with Silc Pig silicone pigments (SmoothOn). We printed the moulds for the large intestine (Figure 4A), base and top skin layer on an Ultimaker S5 $3 \mathrm{D}$ printer using Cura software. We printed the small intestine moulds (Figure 4B), including joints and U-shaped connector moulds, using an Ultimaker S3 3D printer. The moulds were printed in generic polylactic acid at a layer height of $0.22 \mathrm{~mm}$ with $20 \%$ triangular infill.

We made the base, measuring $200 \mathrm{~mm} \times 250 \mathrm{~mm} \times$ $10 \mathrm{~mm}$, by pouring $500 \mathrm{~mL}$ of silicone into a mould created with Fusion $360 \mathrm{CAD}$ software (Autodesk).

We created the top skin piece, measuring $330 \mathrm{~mm} \times$ $290 \mathrm{~mm} \times 10 \mathrm{~mm}$, in 3 layers. The first layer is flesh-tone Ecoflex 00-30 silicone (Smooth-On) embedded with power mesh, the next layer is Ecoflex Gel coloured yellow,

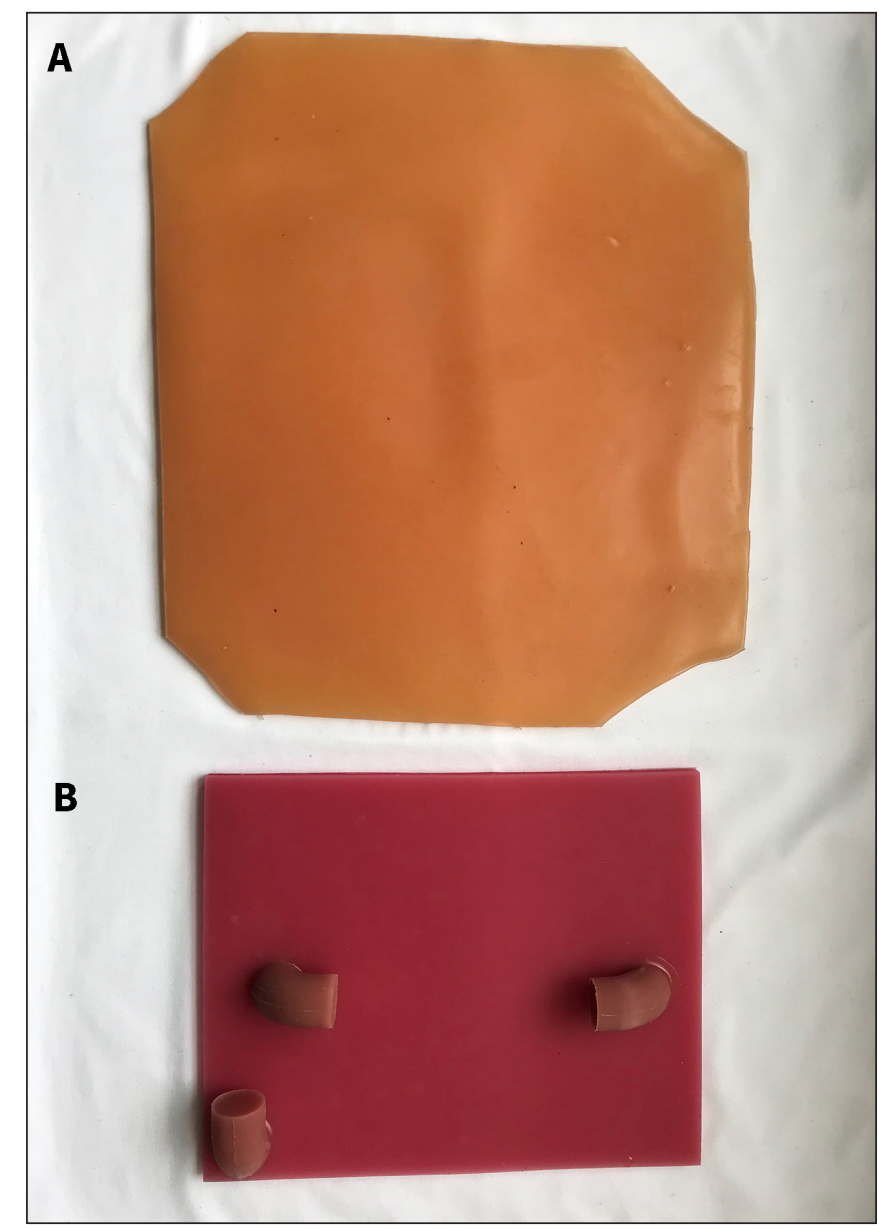

Fig. 1. Simulated abdominal skin (A) and simulator base (B). 


\section{RECHERCHE}

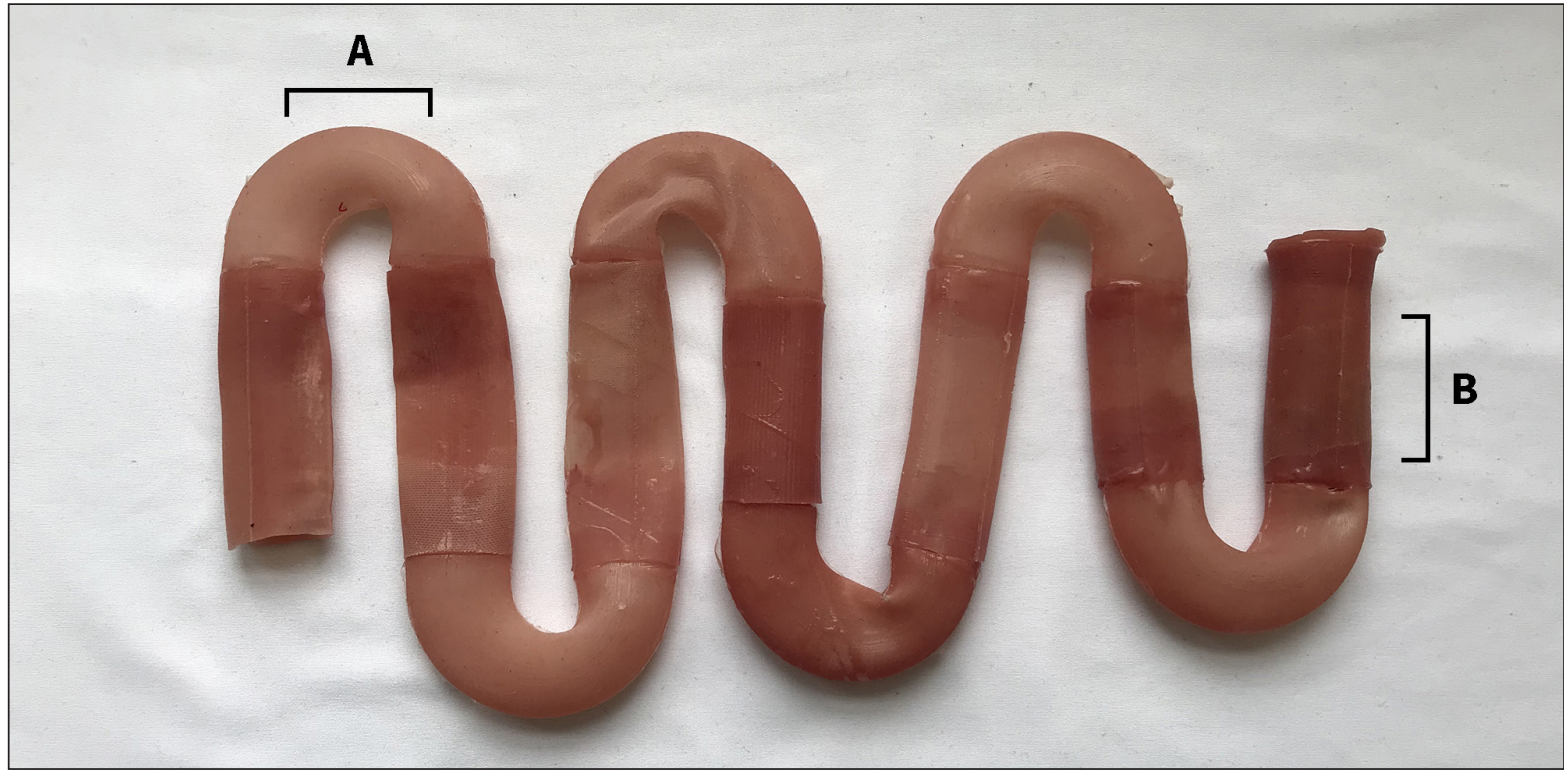

Fig. 2. Small intestine model. U-shaped connectors (A) are used to connect straight joints (B).

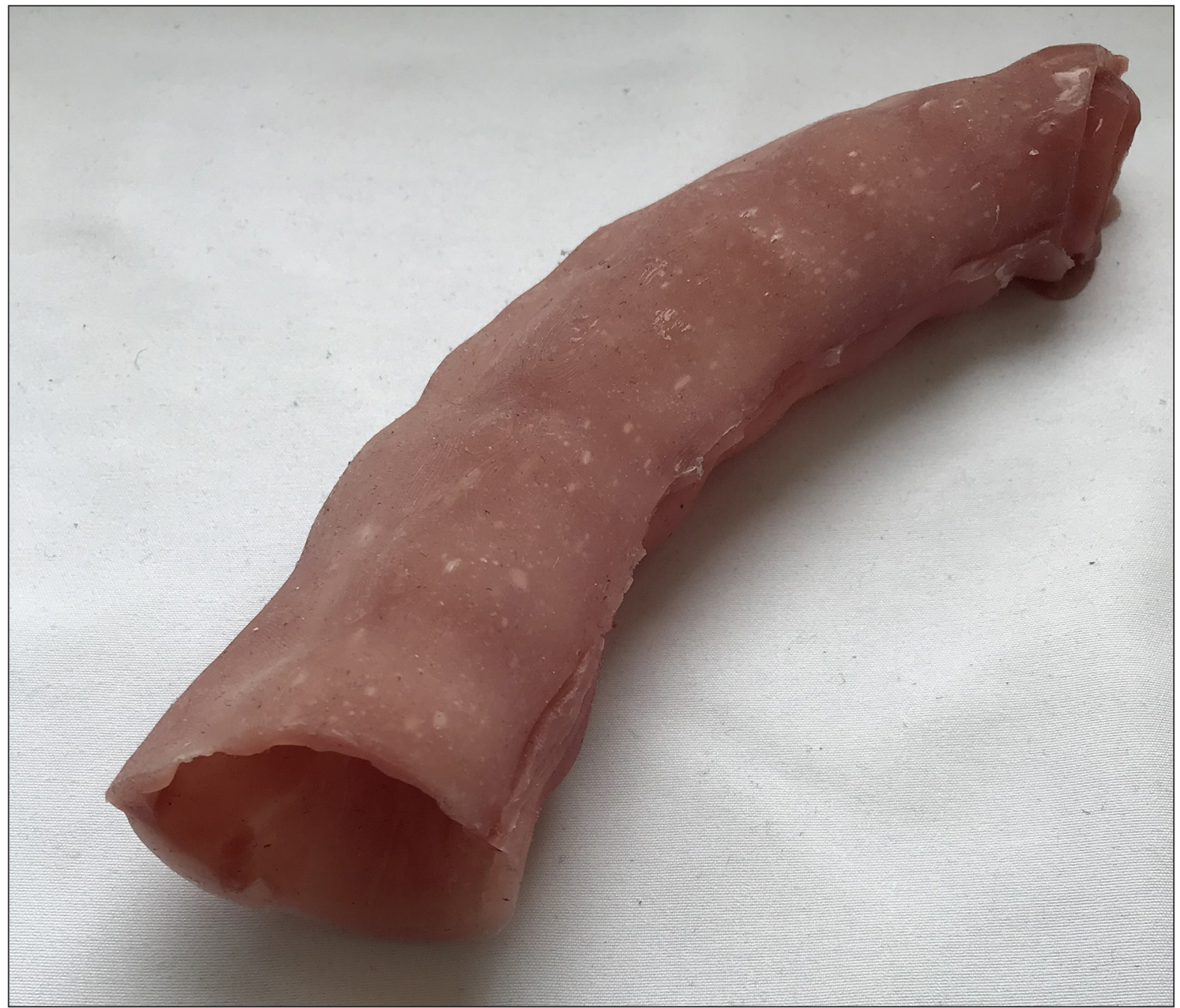

Fig. 3. Large intestine model. 


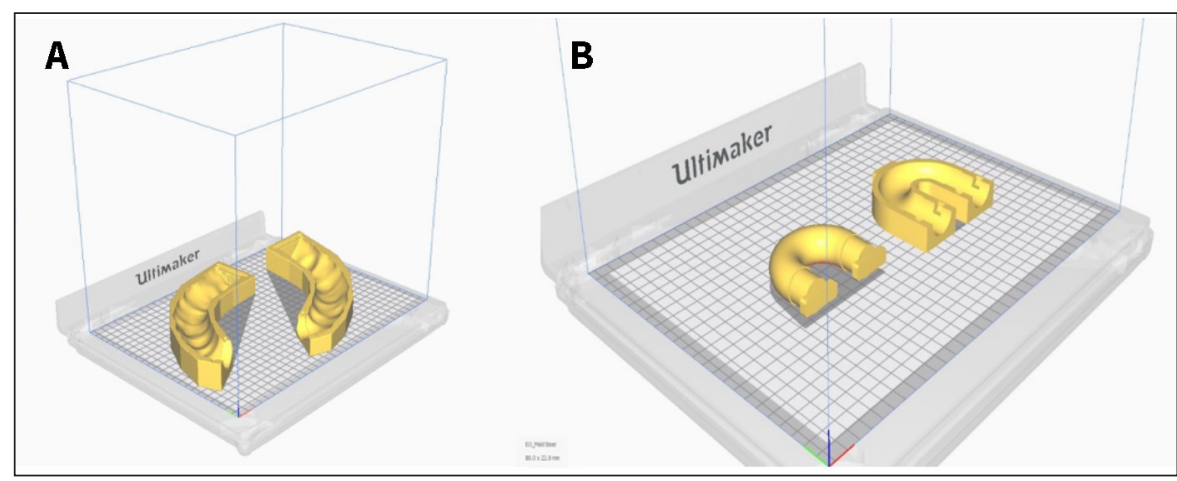

Fig. 4. Three-dimensional printing preview of large intestine segment mould $(A)$ and small intestine segment mould (B).

and the top layer is Ecoflex 00-30 silicone coloured red. These layers are meant to simulate skin, fat and muscle, respectively.

The mould used to make the small intestine consisted of 3 parts. The mould was assembled and filled with bloodcoloured silicone. We moulded the U-shaped connectors using a 3-part mould and Ecoflex 00-30 silicone. The purpose of the connectors was to join the straight intestine pieces to make a single long, winding intestine. We made the small intestine joints using blood-coloured silicone poured into a 2-part mould. We then connected the joints to the base using a small amount of silicone.

The mould used to make the large intestine consisted of 2 parts. Silicone was thickened with a few drops of THI-VEX (Smooth-On) so that it could be brushed onto the walls of either side of the mould, in order to create a hollow object with complex geometry. We then joined the 2 parts together using a small amount of silicone.

Initially, the simulator was to be designed based on computed tomography scans of healthy human bowel. This approach introduced technical issues and produced a model that did not resemble the soft tissue of human bowel closely enough. We then employed a second approach using Fusion 360 CAD software to design the model based on healthy anatomy references and expert input. An initial iteration of the model was then evaluated by a general surgeon (S.Q.), who suggested design modifications to improve the realism of the model.

The cost of the trainer ranges from $\$ 2.67$ to $\$ 131$, depending on which aspects of the model one prefers to include. When we created the model, we made a layer of "skin," at a cost of about $\$ 68$, that can be used when the model is used in an FLS Trainer Box. This was not formally tested in this study and is not required to perform the anastomosis. In addition, we created a large bowel segment that can be added to the trainer box to improve realism; this was also not formally tested. The cost to produce the large intestine was $\$ 9$. The base created to attach to the small intestine trainer has a one-time cost of about $\$ 42.17$. The smallest unit that can be used to perform anastomosis includes 2 straight segments and 1 round seg- ment. The cost to produce this unit was $\$ 2.67$. The bowel anastomosis simulator tested in this study included 6 round segments, 7 straight segments, and 2 free-standing straight segments. The cost of this longer version of the model (which can be used more times) was $\$ 12.78$. If the base is desired, the total cost would be $\$ 54.95$. This cost includes materials only.

\section{Participants and evaluation}

The bowel anastomosis simulator was evaluated by 9 experts in general surgery to determine the level of realism of the elements and tissues and of the simulator in general, and whether the simulator was appropriate for use in training in general surgery. Three senior residents (postgraduate year 4 or 5) and 6 staff general surgeons participated in the evaluation. Four participants were located at the Health Sciences Centre, St. John's, Newfoundland and Labrador, and 5 at Victoria General Hospital, Halifax, Nova Scotia. The participants at the St. John's location were selected by means of the snowball sampling technique: ${ }^{13} 1$ of the authors (S.Q.) recommended an expert, who provided the names of 3 other experts. We selected participants at the Halifax location by contacting the offices of staff listed on the Dalhousie University General Surgery staff webpage; potential participants were also recommended by a surgeon already known to the research group.

Participants were given the bowel anastomosis simulator for an unlimited amount of time to perform an anastomosis. They were instructed to evaluate the model as an anastomosis trainer and were given permission to manipulate the model in whichever way they saw fit. When participants had finished manipulating the anastomosis trainer, they no longer had access to it. Participants manipulated the small intestine segments; the large bowel segment was designed mostly to increase the visual realism of the model if used in an FLS Trainer Box.

Participants were then asked to complete 2 surveys (Table 1). Survey 1 addressed face validity, defined as a measure of how realistic the simulator is compared to what 


\begin{tabular}{l} 
Table 1. Surveys evaluating bowel anastomosis simulation \\
model \\
\hline Survey item \\
\hline Survey 1: Evaluation of product quality (face validity) \\
\hline The flexibility of the model is appropriate for training \\
\hline The texture of the model is appropriate for training \\
\hline The size of the model is appropriate for training \\
\hline The colour of the model is appropriate for training \\
\hline The wall thickness of the model is appropriate for training \\
\hline The layers seen in the model are appropriate for training \\
\hline Survey 2: Evaluation of training potential (content validity) \\
\hline Using the BAS will help to increase the trainee's competence \\
\hline Using the BAS will help to increase the trainee's confidence \\
\hline $\begin{array}{l}\text { Witnessing the trainee's performance on the BAS will increase my } \\
\text { confidence in their ability to assist in the operating room }\end{array}$ \\
\hline $\begin{array}{l}\text { Witnessing the trainee's performance on the BAS will increase my } \\
\text { confidence in their ability to perform the procedure (or skills trained on the } \\
\text { model) in the operating room }\end{array}$ \\
\hline $\begin{array}{l}\text { The BAS would be a valuable addition to current simulation-based medical } \\
\text { education }\end{array}$ \\
\hline BAS = bowel anastomosis simulator. \\
\hline
\end{tabular}

it is designed to simulate; ${ }^{14}$ this was generally based on visual and textural components of the model. In this case, the participants evaluated how similar the bowel anastomosis simulator is to human bowels. Survey 2 addressed content validity, which refers to how useful the simulator is for training purposes. ${ }^{15}$ The participants rated the survey items using a 5 -point Likert scale ranging from 1 ("strongly disagree") to 5 ("strongly agree"). In addition, they were asked "What revisions, if any, would you suggest to improve the functionality of this trainer?" The survey design was based on a previously published study. ${ }^{9}$

This project did not require ethics approval, as the Newfoundland and Labrador Health Research Ethics Authority determined that it fell under the category of product improvement/quality improvement.

\section{Results}

Eight participants chose to suture the model, and 1 chose to use a surgical stapler.

Figure 5 and Figure 6 show the mean ratings for surveys 1 and 2, respectively. The overall average score for product quality was 3.58. Overall, the simulator was regarded as highly realistic. The layers of the simulator received the lowest score: the mean score for the number of layers and resulting appropriateness for training was 2.11 .

Similarly, the simulator was rated as being useful for training, with an overall average score of 3.98. In general, the participants agreed that the simulator would be a valuable addition to current simulation-based medical education, with an average score of 4.11, which was the highest score observed in the evaluation of the simulator.

In response to the open-ended question regarding potential revisions to improve the functionality of the

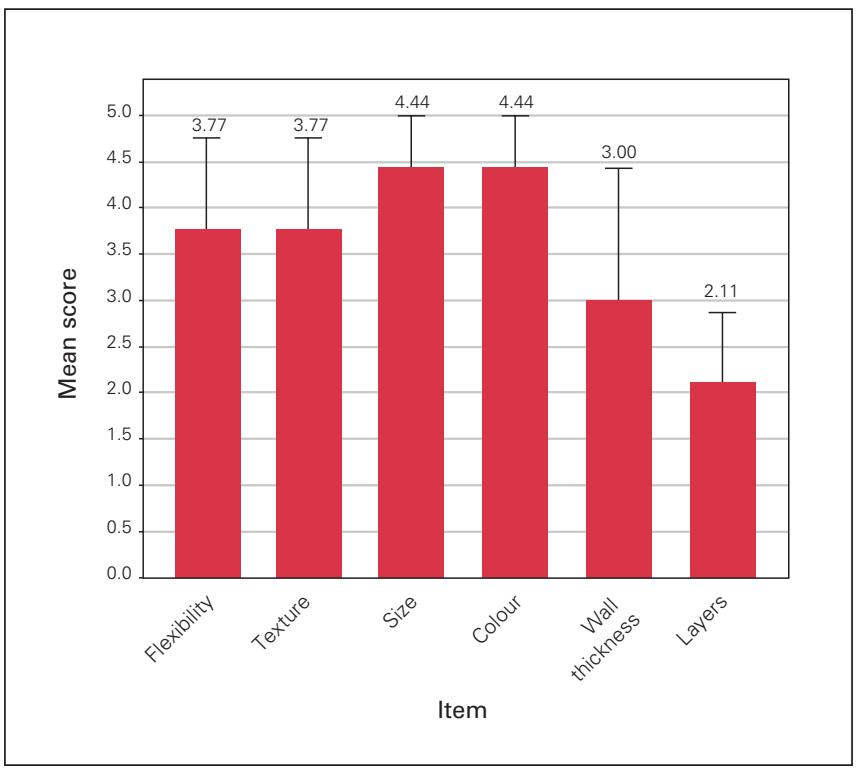

Fig. 5. Mean scores for quality (face validity) of bowel anastomosis simulator. The participants rated each item using a 5-point Likert scale ranging from 1 ("strongly disagree") to 5 ("strongly agree"). Error bars represent standard deviations.

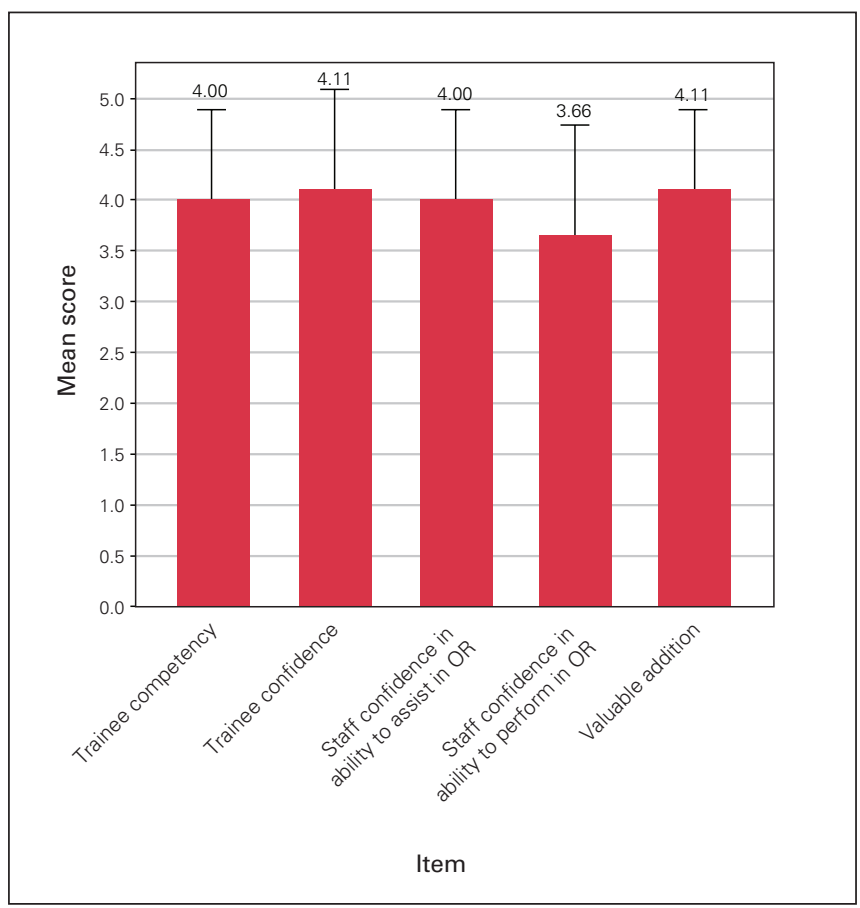

Fig. 6. Mean scores for training potential (content validity) of bowel anastomosis simulator. The participants rated each item using a 5-point Likert scale, ranging from 1 ("strongly agree") to 5 ("strongly disagree"). OR = operating room. Error bars represent standard deviations.

model, 6 participants suggested increasing the number of mucosa layers, 2 suggested increasing the thickness of the simulator, 1 suggested decreasing the resistance of the silicone, and 1 suggested increasing the resistance of the silicone. 


\section{Discussion}

In this pilot study, the participants generally agreed that using the bowel anastomosis simulator would help to increase surgical trainee competency. This indicates that, despite lower scores in some areas such as the number of mucosal layers or texture, experts believed that the simulator would be useful in training. The experts also generally agreed that the simulator would be a valuable addition to current simulation-based medical education. Despite the clear differences between silicone and real intestinal mucosa, which are evident in some of the scores, experts felt that the model was useful and could improve surgical trainees' ability to perform anastomosis.

There were 2 major aspects of the model that were scored poorly and commented on. First, participants indicated that the simulator did not provide enough layers; the consensus was that another layer was needed in order to better simulate intestinal mucosa. This would be an important change to consider in future iterations of the model. Second, some participants commented that the wall was too thick or too thin. This may have been due to inconsistencies in the pouring of the silicone and will need to be addressed in future studies. Potential future iterations of the simulator could provide 2 or 3 thickness variations in order to determine the best thickness to use in subsequent models.

It was discovered during the study that the bowel anastomosis simulator is physically compatible with surgical staples and can be used for practising stapled anastomosis, as well as hand-sewn anastomosis. Further study is needed to determine the face and content validity of the model when used with staples. Other future areas of research include the use of the simulator for laparoscopic training purposes. It will be important to evaluate the use of the simulator in a Fundamentals of Laparoscopic Surgery trainer box in order to assess face and content validity when the model is used laparoscopically.

Despite the imperfect nature of this prototype of the bowel anastomosis simulator, experts felt that practice on this model may increase competency. With the information and critiques obtained in this study, future iterations of the simulator should provide an improved, useful tool for learners and teachers within general surgery.

Once validated, the design presented here will be available to academic and other not-for-profit organizations free of cost through an online database. Institutions with access to a $3 \mathrm{D}$ printer will then have the ability to print their own moulds and models. In addition, because institutions will have access to the design and mould, they will be able to alter the design to suit their needs (for example, a model could be thickened to simulate diseased bowel by increasing the amount of silicone poured). This provides more opportunity for customization of the model and also removes the concern of shipping costs.

\section{Limitations}

A major limitation of this study is the lack of control group comparisons, such as comparisons of the bowel anastomosis simulator to human bowel, as well as to other currently available simulators. Owing to the goals and nature of this pilot study, control groups were not used. This will be an important area of future exploration. In addition, the results indicate only the opinions of experts; further study is required to determine whether the simulator truly can improve variables such as learner competency in a simulated learning environment.

\section{Conclusion}

The bowel anastomosis simulator developed with the use of $3 \mathrm{D}$ printing and silicone pouring that we describe may provide an affordable solution to the problems encountered when using other simulators, such as lack of realism, difficulty in standardization, inability to customize the model using specific patient imaging and cost. Our simulator was rated by experts as realistic in terms of texture, ability to introduce variability, and ability to use real patient scans and data to produce customized models. Therefore, it is possible that simulators such as the one we describe may fill the realism and affordability gap in simulation-based education.

Affiliations: From Memorial University of Newfoundland, St. John's, Nfld. (Oxford, Walsh, Bungay, Quigley); and the University of Ottawa Institute of Technology, Oshawa, Ont. (Dubrowski).

Competing interests: None declared.

Contributors: K. Oxford, G. Walsh, J. Bungay and A. Dubrowski designed the study. K. Oxford acquired the data, which K. Oxford and S. Quigley analyzed. K. Oxford, G. Walsh, J. Bungay and A. Dubrowski wrote the manuscript, which K. Oxford, G. Walsh, S. Quigley and A. Dubrowski critically revised. All authors gave final approval of the article to be published.

Content licence: This is an Open Access article distributed in accordance with the terms of the Creative Commons Attribution (CC BYNC-ND 4.0) licence, which permits use, distribution and reproduction in any medium, provided that the original publication is properly cited, the use is noncommercial (i.e., research or educational use), and no modifications or adaptations are made. See: https://creativecommons. org/licenses/by-nc-nd/4.0/.

Funding: This work was supported by the Atlantic Canada Opportunities Agency Business Development Program. Adam Dubrowski is supported by a Canada Research Chair for Health-Care Simulation.

\section{References}

1. Koopmann MC, Heise CP. Right hemicolectomy. In: Illustrative bandbook of general surgery. London (UK): Springer London; 2009: 149-57.

2. Inpatient hospitalizations, surgeries, newborns and childbirth indicators, 2016-2017. Ottawa: Canadian Institute for Health Information; 2018. Available: https://secure.cihi.ca/free_products/hospch-hosp -2016-2017-snapshot_en.pdf (accessed 2021 Aug. 24).

3. Manuel-Palazuelos JC, Riaño-Molleda M, Ruiz-Gómez JL, et al. Learning curve patterns generated by a training method for laparoscopic small bowel anastomosis. Adv Simul 2016;1:16. 
4. Daams F, Luyer M, Lange JF. Colorectal anastomotic leakage: aspects of prevention, detection and treatment. World 7 Gastroenterol 2013;19:2293-7.

5. Kirchhoff P, Clavien PA, Hahnloser D. Complications in colorectal surgery: risk factors and preventive strategies. Patient Saf Surg 2010;4:5.

6. Nemeth ZH, Lazar EL, Paglinco SR, et al. Experience of general surgery residents in the creation of small bowel and colon anastomoses. 7 Surg Educ 2016;73:844-50.

7. Rowse PG, Ruparel RK, Aljamal YN, et al. Video skills curricula and simulation: a synergistic way to teach 2-layered, hand-sewn small bowel anastomosis. 7 Surg Educ 2015;72:1057-63.

8. Williams A, McWilliam M, Ahlin J, et al. A simulated training model for laparoscopic pyloromyotomy: Is $3 \mathrm{D}$ printing the way of the future? F Pediatr Surg 2018;53:937-41.

9. Goudie C, Shanahan J, Gill A, et al. Investigating the efficacy of anatomical silicone models developed from a $3 \mathrm{D}$ printed mold for perineal repair suturing simulation. Cureus 2018;10:e3181.
10. D'Angelo ALD, Cohen ER, Kwan C, et al.; Association for Surgical Education. Use of decision-based simulations to assess resident readiness for operative independence. Am F Surg 2015;209: 132-9.

11. Egle JP, Malladi SVS, Gopinath N, et al. Simulation training improves resident performance in hand-sewn vascular and bowel anastomoses. F Surg Educ 2015;72:291-6.

12. von Rundstedt FC, Aghazadeh MA, Scovell J, et al. Validation of a simulation-training model for robotic intracorporeal bowel anastomosis using a step-by-step technique. Urology 2018;120: 125-30.

13. Goodman LA. Snowball sampling. Ann Math Stat 1961;32:148-70.

14. Sessa L, Perrenot C, Xu S, et al. Face and content validity of Xperience ${ }^{\mathrm{TM}}$ Team Trainer: bed-side assistant training simulator for robotic surgery. Updates Surg 2018;70:113-9.

15. Bartellas M. Three-dimensional printing and medical education: a narrative review of the literature. Univ Ottawa 7 Med 2016;6:38-43. 